\title{
The Effect of Variation of Amperes and Water Backing Technique on Microstructure, Mechanical Properties, and Dimensional of Welding Process on Crosshead Valve With GTAW Method
}

\author{
Rahmat Ashari ${ }^{1, a)}$, Aji Ridhotullah S. ${ }^{2}$, Sulistijono ${ }^{3}$, Rocky Andiana ${ }^{4}$, Yoel Rizky ${ }^{5}$ \\ Material and Metallurgical Engineering, Institut Teknologi Kalimantan, Soekarno-Hatta KM. 15 Balikpapan Utara, \\ Balikpapan 76127, Indonesia \\ a)06131008@itk.ac.id
}

\begin{abstract}
In this study, evolution of microstructural, hardness value, and dimensional crosshead valve that has been welded with $\mathrm{Ni}$-Cr-B-Si-C alloys deposit are investigated. Ni-Cr-B-Si-C alloys has deposited to replace nickel alloys on component that have wear. The process that used is GTAW welding process with variation of amperes and with or without using water backing technique. Result from this study, on weld metal microstructure with variation of heat input and water backing method made same structure like original materials. On base metal microstructure, resulting same structrue as original material that consist of ferrite and pearlite. However, on HAZ which used 140 A on welding current and water backing method produced martensite structure. The greater heat input make a greater hardness value on weld metal and water backing can keep the original hardness from material. In addition, heat input and water backing that used in this processs not cause a deformation on crosshead components result from dimensional test which still suitable with original component specification.
\end{abstract}

Keywords: Welding, GTAW, Crosshead, S55C, Nickel Alloy, Ni-Cr-B-Si-C

\section{INTRODUCTION}

Ni-Cr-B-Si-C alloys is a nickel based alloys that widely used as layer materials to protect from wear and corrosion that can be happen (Ming, Lim, \& Chen, 1998). This alloys has a goofd hardness and toughness because a content of $\mathrm{Cr}, \mathrm{B}, \mathrm{Si}$, and C. Generally, these nickel-based alloys have been widely used and deposited on substrate materials with various techniques.

Crosshead valve is one of the component that installed on an engine. On 12V140E-3 engine from komatsu HD 785-7 unit, there is a crosshead valve component that originally made from S55C which have an part which that was hardened by induction hardening process that make it have a great hardness value and the top of this component has a deposit material from Ni-Cr-B-Si-C alloys. These alloys was deposited on this component to protect it from contact with rocker arm that can caused a wear. Wear is one of the failures that occur due to contact and relative movement to solid, solution, or gas so that the material surface is wasted or removed (Becker et al., 2002). From that problem, it is necessary to find a reparation method the parts so that the components can be reused and have original product specifications.

Welding is a metallurgical bond on metal or metal alloy joints that are carried out in a melted or liquid state according to the definition of Deutsche Industrie Normen (DIN). The development of the welding process has been carried out based on a combination of temperature and pressure from high temperature without pressure to high temperature with low pressure (Khan, 2007). Repair using welding can be done as a procedure that produces useful and safe components. Welding repairs can be categorized into three: repair of welding defects, repair of failed components, and repair of wear components. Cladding, different metal joining, and surface hardening are the common processes in welding method of wear components. Therefore, in this study, we will investigate the microstructural 
changes, the hardness values, and the dimensions of the crosshead valve components of the welded products with the deposit of Ni-Cr-B-Si-C alloy materials as a substitute of nickel alloys in wear components using GTAW method with Large variations of current as well as in the process carried out with or without water backing technique.

\section{MATERIALS AND METHODS}

\section{Materials}

The material that used in this research is the crosshead valve component of the engine 12V140E-3 unit Komatsu HD 785-7. These components made from S55C which have an area which that was hardened by induction hardening process and the top of the part there is a deposit material which made from N-Cr-B-Si-C alloys. For the material used as a nickel substitute replacement material on the crosshead valve component, the NCR-G6MOD rod of Tokuden Ltd. selected as deposit material. The composition and mechanical properties of NCR-G6MOD are presented in Tables 1 and 2. In the welding process, EWTh-2 electrodes which have AWS A5.12 standards are used.

TABLE 1. Chemical Composition of Filler NCR-G6MOD

\begin{tabular}{cccccc}
\hline $\mathbf{C} \%$ & $\mathbf{S i} \%$ & $\mathbf{N i \%}$ & $\mathbf{C r} \%$ & $\mathbf{F e} \%$ & $\mathbf{B} \%$ \\
\hline 0,05 & \multirow{2}{*}{4,63} & Balanced & 7,98 & 3,26 & 2,81 \\
\hline
\end{tabular}

TABLE 2. Chemical Composition of Filler NCR-G6MOD

\begin{tabular}{cc}
\hline Filler & Kekerasan \\
\hline NCR-G6MOD & $52-60 \mathrm{HRC}$ \\
\hline
\end{tabular}

\section{Tools}

The tools used in this research are cutting tool, grinding and polishing machine, manual grinding and surface grinding, precision cutting machine, microvickers hardness testing machine, optical microscope, GTAW welding machine, OAW welding machine, and CMM (Coordinate Measuring Machine).

\section{Welding Process}

The welding process is carried out on the crosshead components that wear on the nickel alloy region. Prior to the welding process, the specimen is performed cleaning and marking process to avoid any impurities on the component. Furthermore, the specimen is preheated by heating the specimen at a temperature of $120^{\circ} \mathrm{C}$ to prevent cracking due to the welding process. The welding process itself is done in two circumstances that is by using water backing and without water backing which each circumstances is carried out with variation of ampere value $100 \mathrm{~A}, 120 \mathrm{~A}$, and 140 A by using welding parameters shown in table 3 . Method of water backing is done by dipping component Crosshead valve about $45 \mathrm{~mm}$ deep.

TABLE 3. Welding Paremeters

\begin{tabular}{lc}
\hline Voltage & 15 \\
\hline Polarity & DCEN \\
\hline Travel Speed & $25 \mathrm{~cm} / \mathrm{min}$ \\
\hline Electrode Diameters & $2,4 \mathrm{~mm}$ \\
\hline Filler Diameters & $5 \mathrm{~mm}$ \\
\hline Shielding Gas & Argon $100 \%$
\end{tabular}




\section{Hardness Testing Process}

Hardness testing is performed to determine the hardness distribution in the specimen after welding process on the base metal, heat affected zone (HAZ), induction hardening, and weld metal. Each area is taken by 10 points of indentations. The standard of hardness testing that used is the microhardness method based on ASTM E384 (ASTM International, 2002).

\section{Metallographic Process}

Metallography is performed to analyzing the phase, shape and size of microstructure in the base metal area, heat affected zone and weld metal. It is also to predict the transformation that occurs due to welding process or heat treatment. This process is done by ASTM E3 standard. Stages performed are as follows:

1. Cutting: Cutting the specimen is done by using manual or automatic cutting tool.

2. Mounting: Creating parts on specimens to facilitate the handling of specimens during the grinding process.

3. Grinding: The process of refining the surface of the specimen with silicon carbide sandpaper starting from grade 60 to 2000 so that will be obtained a smooth surface.

4. Polishing: Polish the specimen with alumina paste in order to make sure there are no scratches on the surface.

5. Etching: Dipping the surface of the specimen into the etching solution to facilitate the process of observing the structure. The etching solution that used is Nital.

6. Observation process by optical microscope by doing some magnification.

\section{CMM Measurement}

Coordinate Measuring Machine (CMM) is a 3D tool used for measuring the physical geometry of an object. Measurements are carried out on the specimen after the deposit and the grinding process to analyze the presence or absence of deformation that occurs due to the welding process and in accordance with the standard. Tests conducted on the area shown Figure 1.
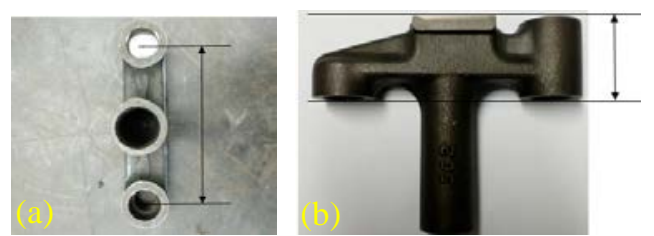

FIGURE 1. Welded component: (a) measurement area 1; (b) measurement area 2

\section{RESULT AND DISCUSSION}

\section{Macrostructure}

In this research, macro observation is done to find out whether or not porosity of the welding crosshead valve component with the influence of the current using water backing method or without using water backing method. Components that have been welded, then cut for further macro observations. The following is the result of observation of the welded components
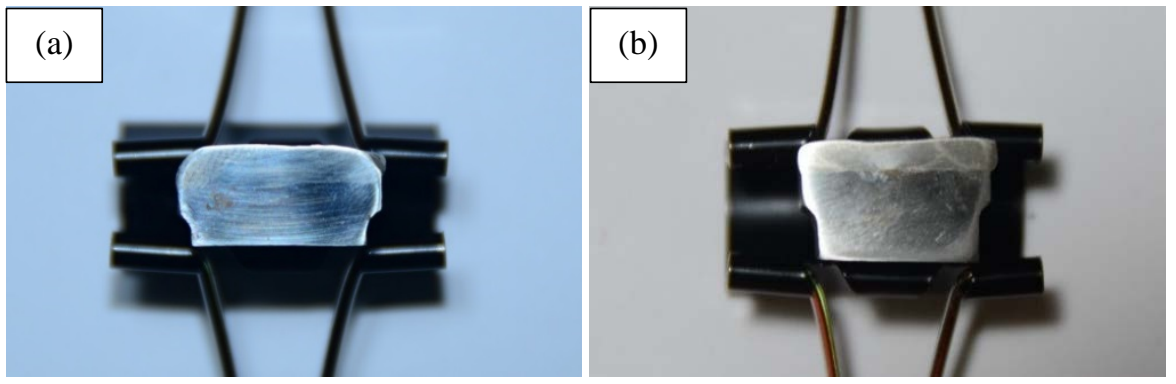

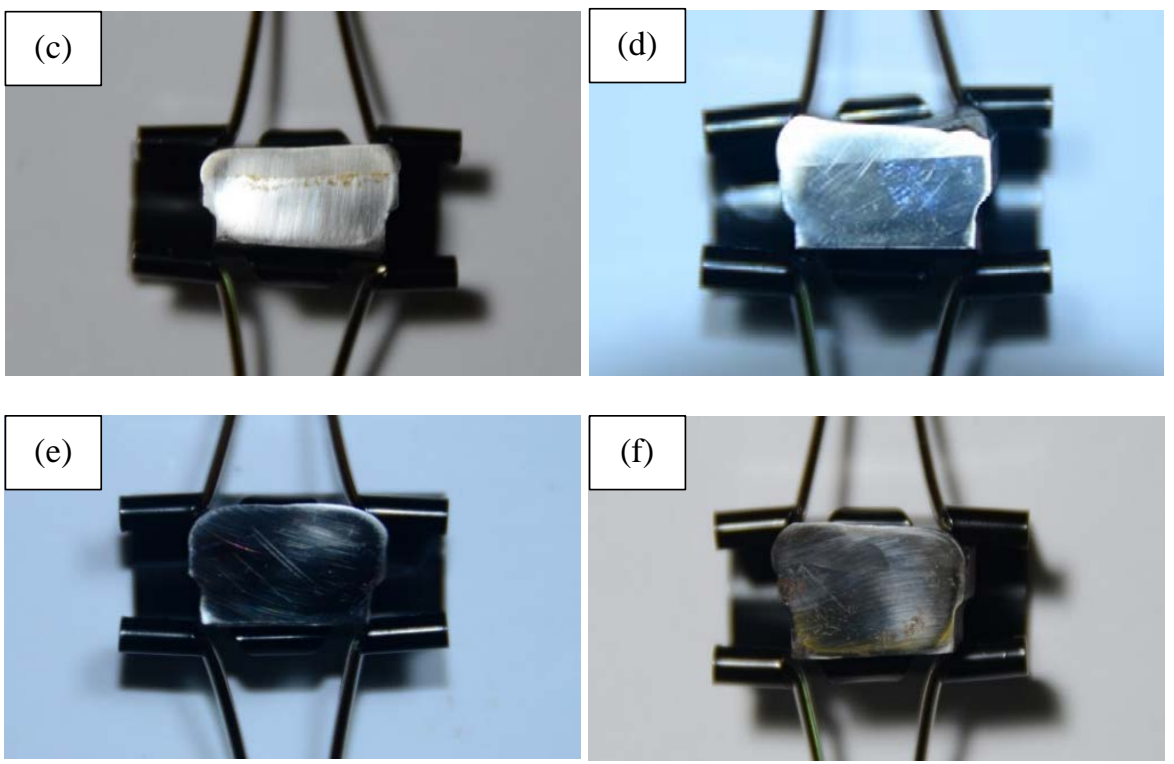

FIGURE 2. Welded components: (a) using water backing with $100 \mathrm{~A}$; (b) without water backing using with $100 \mathrm{~A}$; (c) using water backing with 120 A; (d) without water backing with 120 A; (e) using water backing with 140 A; (f) without water backing with 140 A.

From the results obtained based on macro observations on the welding of the crosshead valve component, there are no presence of porosity, inclusions, or cracks formed on the metal weld and the base metal due to the influence of the current used or whether the use of water backing method on the welding crosshead valve component.

\section{Microstructure Test}

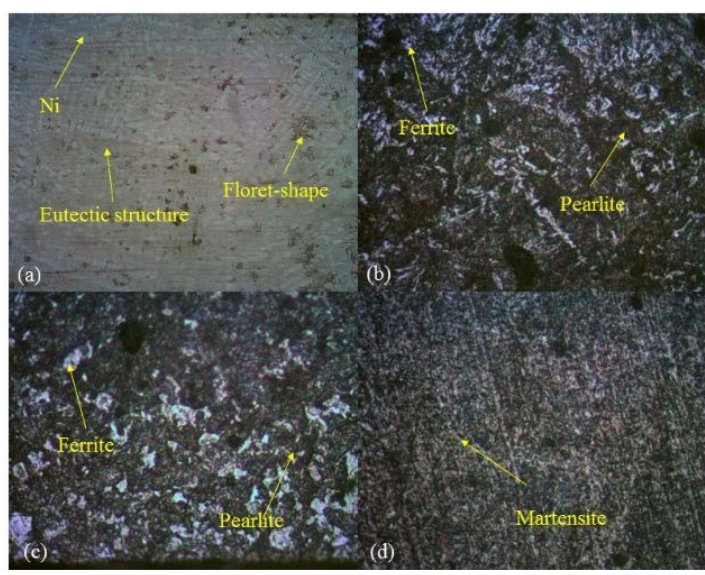

FIGURE 3. Microstructure of welding process with 100 A using water backing: (a) weld metal; (b) HAZ; (c) base metal; (d) induction hardening area. 


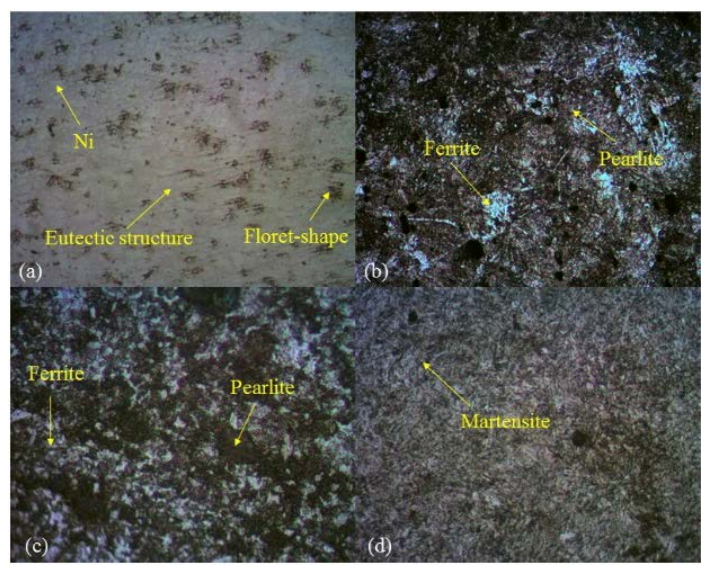

FIGURE 4. Microstructure of welding process with 120 A using water backing: (a) weld metal; (b) HAZ; (c) base metal; (d) induction hardening area.

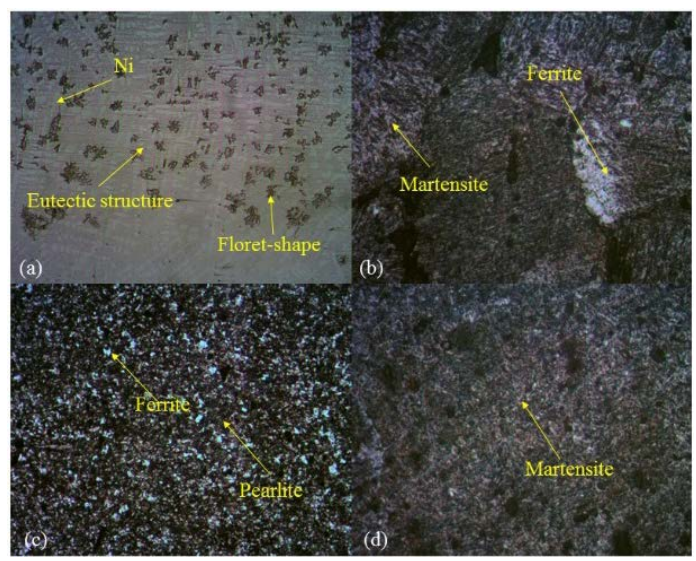

FIGURE 5. Microstructure of welding process with 140 A using water backing: (a) weld metal; (b) HAZ; (c) base metal; (d) induction hardening area.

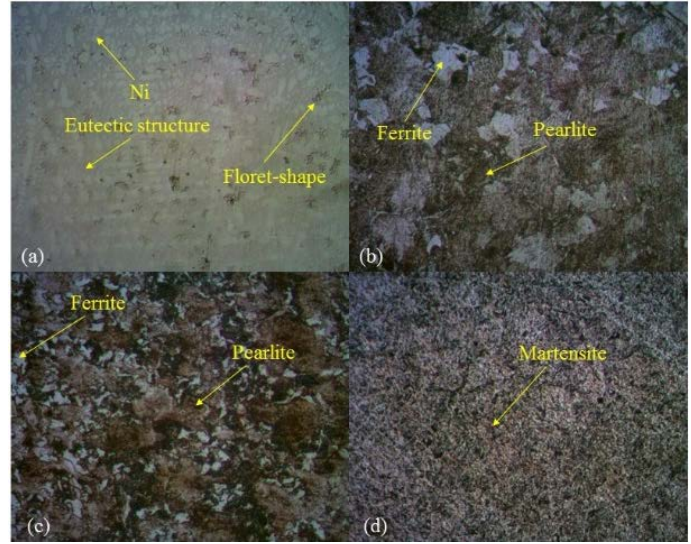

FIGURE 6. Microstructure of welding process using 100 A without water backing: (a) weld metal; (b) HAZ; (c) base metal; (d) induction hardening area. 


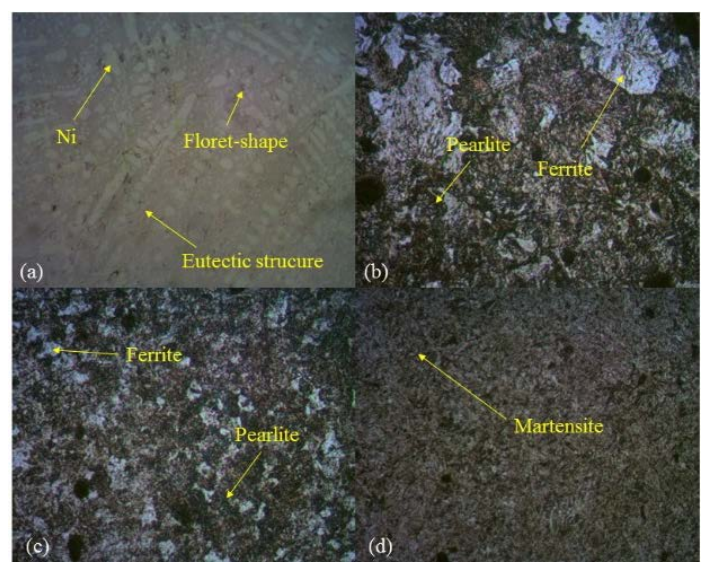

FIGURE 7. Microstructure of welding process using 120 A without water backing: (a) weld metal; (b) HAZ; (c) base metal; (d) induction hardening area.

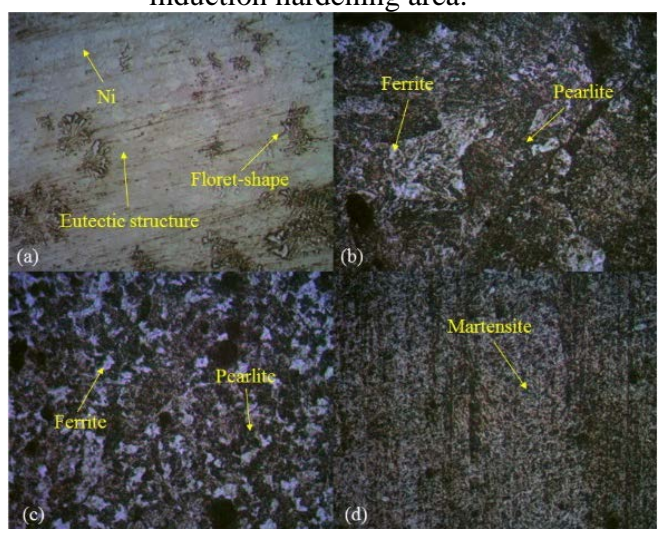

FIGURE 8. Microstructure of welding process using 140 A without water backing: (a) weld metal; (b) HAZ; (c) base metal; (d) induction hardening area.

Figures 3, 4, 5, 6, 7, and 8 are the results of observation of microstructure on the welding of crosshead valve components. The microstructural observations were performed on the areas of weld metal, HAZ, base metal, and induction hardening areas. This is carried out to analyze the changes caused by the material deposit process on the component. From the observation of microstructure, the weld metal area of the welding process with method consists of nickel dendrites, eutectic structure, and floret-shape. In the HAZ region, the result of welding process using or without a water backing method with a predetermined variation of the specified currents forms a pearlite and ferrite structure in which the pearlite structure is characterized by a dark and ferrite region characterized by a brightly colored area. However, in the HAZ area the result of welding process using water backing method with a large current of 140 A formed martensitic structure. In the base metal region, of all welding parameters used to produce the structure of pearlite and ferrite structures. In the induction hardening area, the welding process uses a water backing method with a current of $100 \mathrm{~A}, 120 \mathrm{~A}$, and 140 formed a martensite structure. However, in the welding process without the use of water backing with a predetermined current, the three have a finer martensite structure when compared with the original material and the result of the process using water backing.

\section{Hardness Test}

In order to know the hardness value of the welding component by using parameters that have been done, the hardness test is done on the area of metal welding, HAZ, base metal, and induction hardening area. Hardness test is done as much as 10 times indentation in each area to be tested. Here is a table of results of hardness testing of each parameter that has been in the average. 
TABLE 4. Hardness test result on welded component using 100 A with water backing

\begin{tabular}{cc}
\hline Area & $\begin{array}{c}\text { Hardness value } \\
\text { (HRC) }\end{array}$ \\
\hline Weld Metal & 53,89 \\
\hline HAZ & 30,88 \\
\hline Induction Hardening & 58,11 \\
\hline Base Metal & 25,45 \\
\hline
\end{tabular}

TABLE 5. Hardness test result on welded component using 120 A with water backing

\begin{tabular}{cc}
\hline Area & $\begin{array}{c}\text { Hardness value } \\
\text { (HRC) }\end{array}$ \\
\hline Weld Metal & 56,15 \\
\hline HAZ & 36,04 \\
\hline Induction Hardening & 59,25 \\
\hline Base Metal & 27,74 \\
\hline
\end{tabular}

TABLE 6. Hardness test result on welded component using 140 A with water backing

\begin{tabular}{cc}
\hline Area & $\begin{array}{c}\text { Hardness value } \\
\text { (HRC) }\end{array}$ \\
\hline Weld Metal & 58,17 \\
\hline HAZ & 57,16 \\
\hline Induction Hardening & 58,17 \\
\hline Base Metal & 23,99
\end{tabular}

TABLE 7. Hardness test result on welded component using 100 A without water backing

\begin{tabular}{cc}
\hline Area & $\begin{array}{c}\text { Hardness value } \\
\text { (HRC) }\end{array}$ \\
\hline Weld Metal & 54,74 \\
\hline HAZ & 32,69 \\
\hline Induction Hardening & 52,67 \\
\hline Base Metal & 23,18 \\
\hline
\end{tabular}

TABLE 8. Hardness test result on welded component using 120 A without water backing

\begin{tabular}{cc}
\hline Area & $\begin{array}{c}\text { Hardness value } \\
\text { (HRC) }\end{array}$ \\
\hline Weld Metal & 56,33 \\
\hline HAZ & 34,9 \\
\hline Induction Hardening & 51,93 \\
\hline Base Metal & 23,41
\end{tabular}

TABLE 9. Hardness test result on welded component using 140 A without water backing

\begin{tabular}{cc}
\hline Area & $\begin{array}{c}\text { Hardness value } \\
\text { (HRC) }\end{array}$ \\
\hline Weld Metal & 57,28 \\
\hline HAZ & 34,56 \\
\hline $\begin{array}{c}\text { Induction } \\
\text { Hardening }\end{array}$ & 43,26 \\
\hline Base Metal & 25,82
\end{tabular}

To further clarify the comparison of hardness values obtained from the welding results with the variation of parameters used in each region, the figures 9 and 10 show the graph of the comparison of hardness values obtained in each region based on the parameters used. 


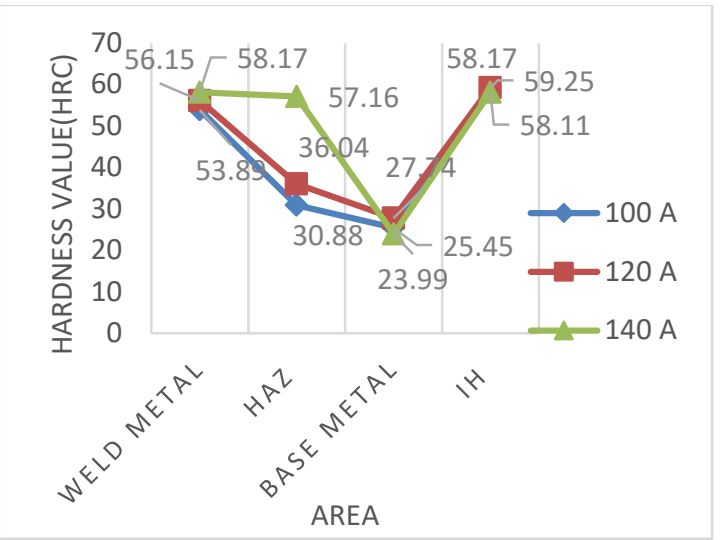

FIGURE 9. Graph of comparison hardness value welded specimen with using water backing technique.

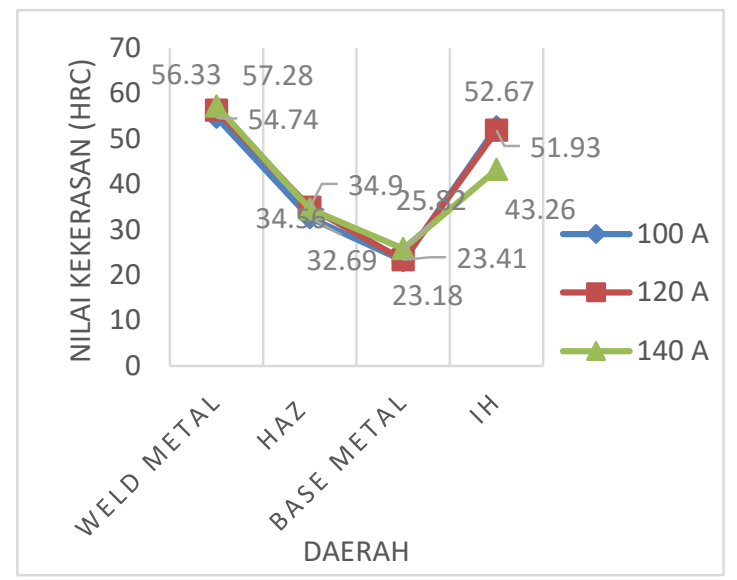

FIGURE 10. Graph of comparison hardness value welded specimen without using water backing technique.

\section{Dimensional Test}

The dimensional test is performed on the area as shown in Figure 1. This dimension test is performed to determine whether or not deformation occurs as a result of the welding process and to adjust whether the welding component is still in accordance with the standard size. Tables 10,11, 12, and 13 show the results of testing the results of the welding process with different welding parameters.

TABLE 10. Result dimensional measurement on area 1 of welded speciment using water backing technique

\begin{tabular}{cccc}
\hline Amp & $\begin{array}{c}\text { Result } \\
(\mathbf{m m})\end{array}$ & $\begin{array}{c}\text { Standard } \\
(\mathbf{m m})\end{array}$ & Criteria \\
\hline 1000 & 61.44 & & $\mathrm{OK}$ \\
\cline { 1 - 2 } $\mathbf{1 2 0}$ & 61.52 & $61.5 \pm 0.2$ & $\mathrm{OK}$ \\
\cline { 1 - 2 } $\mathbf{1 4 0}$ & 61.51 & & $\mathrm{OK}$
\end{tabular}

TABLE 11. Result dimensional measurement on area 2 of welded speciment using water backing technique

\begin{tabular}{|c|c|c|c|}
\hline Amp & $\begin{array}{c}\text { Result } \\
\text { (mm) }\end{array}$ & $\begin{array}{c}\text { Standard } \\
(\mathrm{mm})\end{array}$ & Criteria \\
\hline 100 & 22.02 & \multirow{3}{*}{$22 \pm 0.5$} & OK \\
\hline 120 & 22 & & OK \\
\hline 140 & 22.03 & & $\mathrm{OK}$ \\
\hline
\end{tabular}


TABLE 12. Result dimensional measurement on area 1 of welded speciment without using water backing technique

\begin{tabular}{|c|c|c|c|}
\hline Amp & $\begin{array}{c}\text { Result } \\
(\mathrm{mm})\end{array}$ & $\begin{array}{c}\text { Standard } \\
(\mathrm{mm})\end{array}$ & Criteria \\
\hline 100 & 61.51 & \multirow{3}{*}{$61.5 \pm 0.2$} & OK \\
\hline 120 & 61.49 & & OK \\
\hline 140 & 61.53 & & OK \\
\hline
\end{tabular}

TABLE 13. Result dimensional measurement on area 2 of welded speciment without using water backing technique

\begin{tabular}{|c|c|c|c|}
\hline Amp & $\begin{array}{c}\text { Result } \\
\text { (mm) }\end{array}$ & $\begin{array}{l}\text { Standard } \\
(\mathbf{m m})\end{array}$ & Criteria \\
\hline 100 & 22.01 & \multirow{3}{*}{$22 \pm 0.5$} & OK \\
\hline 120 & 22 & & OK \\
\hline 140 & 22.03 & & OK \\
\hline
\end{tabular}

From the results of the dimensional tests performed on region 1 and region 2 on the components of welding using different parameters obtained that there is no change in the dimensions or deformation presence on the component where the results are still in accordance with the standard specification component.

\section{Discussion}

With a variation of current used $100 \mathrm{~A}, 120 \mathrm{~A}$, and $140 \mathrm{~A}$ using GTAW method to deposit NCR-G6MOD filler on S55C material on crosshead valve component obtained heat input of $214.285 \mathrm{~kJ} / \mathrm{s}, 257,142 \mathrm{~kJ} / \mathrm{s}$ and $300 \mathrm{~kJ} / \mathrm{S}$, respectively. Based on the heat input obtained it is also obtained that the width of HAZ is getting bigger along with the increase of heat input generated.

The results of macro observations on the welding of components with variations of current and the with or without using water backing method indicate the absence of cracks, porosity, and inclusions occurring in the welding results of both on the weld metal and the base metal regions. This indicating the parameters used in the welding process with using or without using water backing is good to applied for deposit filler process on the crosshead component to replace of the nickel alloy material previously lost due to the wear on the area.

From the observation of microstructure, in the weld metal area is formed nickel dendrites structure, eutectic structure, and floret-shape. The floret-shape structure itself is formed due to metastable eutectic reactions consisting of $\mathrm{Cr}^{2} \mathrm{~B}_{3}$ and Ni which are formed at a temperature of about $1100^{\circ} \mathrm{C}$ and in the presence of rapid cooling. With increasing heat inputs such as using current of $140 \mathrm{~A}$ and the presence of water backing in the welding process, make this structure presence with large amount and dimension caused by large thermal inputs that can make opportunities for elements to react and fast cooling so that can stand this structure. In the HAZ area, with a current of $140 \mathrm{~A}$ and the presence of water backing, the martensite structure on this region is formed. The existence of water backing providing areas close to the water can make a fast cooling process so a martensite structure may be formed. In the process with other parameters in the HAZ region are generated pearlite and ferrite structures. The existence of larger and dispersed pearlite structures in the HAZ region of any process parameters used can make the hardness value of this area increased. In the base metal region, the resulting structure is pearlite and ferrite with a large variation of the current and the presence or absence of water backing. The existence of the formed ferrite makes the hardness value of the material is not too high or low so its ductility increases while the pearlite structure can cause a high enough hardness value in the base metal region. In the induction hardening area, the process without using water backing and the greater of heat input obtained during the welding process to make the resulting martensitic structure slightly changed where the resulting structure is smoother. This is due to the large heat surrounding the area causing structural changes.

From the results of hardness testing, it is found that the greater the heat input that occurs as well as the existence of water backing make the hardness value obtained in the weld metal region has increased due to the greater heat input given it will make the opportunity for the elements contained in it to form hard phase. In the HAZ region, the hardness value obtained is higher than the base metal due to the impact of heat generated in the welding process and existance of a rapid cooling rate. This can make the atoms in this region distorted to cause residual stress that can increase the hardness. This is also shown in the usage of ampere $140 \mathrm{~A}$ with water backing which also forms a martensite structure which results from rapid cooling due to the use of water backing. While in the induction hardening area, the greater the heat input generated and the absence of water backing makes the hardness value in this area decrease from its 
initial value. This is because the absence of water to withstand the heat generated from the welding process, especially with the greater heat input makes the heat effecting the induction hardening area that makes structural changes so that the value of hardness decreased. This is indicated on the use of welding parameters with a large current of 140 A without water backing which produces the lowest hardness value in induction hardening area which is sebesa 43.26 HRC.

From the results of the dimensional tests performed on region 1 and region 2 on the components of welding using different parameters obtained that there is no change in the dimensions or deformation produced on the component where the results are still in accordance with the standard specification component. Means with the resulting heat input and whether or not water backing is used does not make changes in dimensions or deformation generated in the process of welding components.

\section{CONCLUSION}

From this study, it can be concluded as follows:

1. The use variations of current and use of water backing method on crosshead welding using $\mathrm{Ni}$ - $\mathrm{Cr}$ - B filler on the weld metal area produces the same structure as the original FR - 60 material. In the base metal region, the resulting structure has not changed from the original material which comprises ferrite and pearlite. However, with a current of $140 \mathrm{~A}$ in the HAZ area with water backing method produces a martensite structure which is due to the rapid cooling.

2. The increased use of heat inputs increases the hardness of the weld metal. In addition, the use of water backing can maintain the value of hardness in certain areas of the crosshead compared with not using the water backing process that makes the value of harness decreased.

3. The use variation of current and the existence of water backing technique on crosshead welding process does not cause deformation in the crosshead component where the result of dimension test is done still according to predetermined dimension.

\section{REFERENCES}

ASTM International. (2002). ASTM E 384 Standard Test Method for Microindentation Hardness of Materials. ASTM International ASTM (American Society for Testing and Materials).

Becker, W. T., Shipley, R. J., Lampman, S. R., Scott, W. W., Marquard, E., Lampman, H., \& Riddlebaugh, M. J. (2002). ASM Handbook Volume 11 Failure Analysis and Prevention. ASM Handbook (Vol. 11). Ohio: ASM International.

Khan, M. I. (2007). Welding Science and Technology. Lucknow: New Age International Publisher.

Ming, Q., Lim, L. C., \& Chen, Z. D. (1998). Laser cladding of nickel-based hardfacing alloys. Surface and Coatings Technology, 106(2-3), 174-182. https://doi.org/10.1016/S0257-8972(98)00524-6 